\title{
A DECADÊNCIA IDEOLÓGICA DA BURGUESIA E A DESVALORIZAÇÃO DA PRODUÇÃO CIENTÍFICA NACIONAL
}

\author{
THE IDEOLOGICAL DECADENCE OF BURGUESY AND THE DEVALUE OF \\ NATIONAL SCIENTIFIC PRODUCTION
}

\author{
Saulo Rodrigues Carvalho ${ }^{1}$ \\ Universidade Estadual do Centro-Oeste (UNICENTRO)
}

\section{RESUMO}

Este artigo analisa os aspectos da decadência ideológica da burguesia e sua relação com a desvalorização da produção científica. Parte do pressuposto que o aprofundamento da crise de lucratividade impulsiona o irracionalismo, suas respostas ilusórias e embrutecedoras na retomada dos níveis máximos de exploração. De tal modo, a apologética ao sistema capitalista favorece ao fortalecimento de pseudociências mistificadoras e legitimadoras da forma capital. Num segundo momento, coteja os aspectos da decadência ideológica presentes na formulação do programa "Future-se", proposto pelo MEC. Os imperativos ideológicos do empreendedorismo conduzem a produção da pesquisa nacional, para a reorganização das suas práticas científicas orientadas e limitadas pelo preceito da rentabilidade do mercado.

Palavras-Chave: Decadência Ideológica. Marxismo. Produção Científica. Future-se. Empreendedorismo.

\begin{abstract}
This article analyzes aspects of the ideological decay of the bourgeoisie and its relationship with the devaluation of scientific production. It starts from the assumption that the deepening of the profitability crisis drives irrationalism, its illusory and stultifying responses in the resumption of maximum levels of exploitation. In such a way, apologetics to the capitalist system favors the strengthening of mystifying and legitimating pseudosciences of the capital form. In a second moment, it compares the aspects of ideological decay present in the
\end{abstract}

\footnotetext{
1 Doutor em Educação Escolar pela Faculdade de Ciências e Letras (FCLAR) da Universidade Estadual Paulista "Júlio de Mesquista Filho"- UNESP.Professor do curso de Pedagogia da Universidade Estadual do Centro Oeste do Paraná (UNICENTRO). E-mail: saulorc1982@gmail.com
}

Cadernos GPOSSHE On-line, Fortaleza, v. 2, n. Especial, 2019. 
formulation of the program "Future-se", proposed by MEC. The ideological imperatives of entrepreneurship guide the production of national research, for the reorganization of its scientific practices oriented and limited by the precept of market profitability.

Key Words: Ideological decay. Marxism. Scientific Production. Future-se. Entrepreneurship.

\section{Características fundamentais da decadência ideológica burguesa}

decadência ideológica é uma categoria que representa o afastamento do
compromisso da classe burguesa com a compreensão da realidade social. Marx capitalismo sob os auspícios da burguesia promoveu mudanças profundas em todas as esferas da vida humana, não só mudou fundamentalmente a produção material, mas as artes, as ciências, os costumes, as tradições, exercendo, até a consolidação do seu poder político, "um papel extremamente revolucionário" (MARX e ENGELS, 2009, p.13).

Com a derrota do feudalismo e a universalização do capital, como modo de produção da vida social, a burguesia assume, decididamente, uma postura conservadora e em muitos casos reacionária. A revolução proletária de 1848 na França, foi fundamental para confirmar tais tendências. $O$ amadurecimento da hegemonia burguesa trouxe também o acirramento das lutas de classe, que se tornaram "mais definidas e ameaçadoras" (MARX, 2010, p.24). Desse ponto em diante a filosofia burguesa deixa de buscar conhecer a realidade do modo como ela realmente se apresenta, para admiti-la, ao ponto em que não contradiga a produção capitalista. Marx (2002, p.24) irá dizer no prefácio de $O$ Capital que a ciência econômica burguesa entrava em declínio e que "os pesquisadores desinteressados foram substituídos por espadachins mercenários, a investigação científica imparcial cedeu seu lugar à consciência deformada e às intenções perversas da apologética". Lukács (2010) irá reconhecer Marx como o primeiro a identificar as tendências decadentes da filosofia e economia burguesa, alargando, desse modo, sua compreensão.

Essa liquidação de todas as tentativas anteriormente realizadas pelos mais notáveis
ideólogos burgueses no sentido de compreender as verdadeiras forças motrizes da
sociedade, sem temor das contradições que pudessem ser esclarecidas; essa fuga
numa pseudo-história construída a bel-prazer, interpretadas superficialmente,
deformada em sentido subjetivista e místico, é a tendência geral da decadência
ideológica (LUKÁCS, 2010, p.53)

O subjetivismo e o misticismo são traços fundamentais da decadência ideológica que irá marcar as lutas travadas pela burguesia para a expansão e dominação do capital nos 
séculos XIX, XX e XXI. Imperialismo, chauvinismo, fascismo e nazismo, são expressões mais acabadas da decadência, que compartilham a defesa inconteste do capital como forma soberana de sociabilidade.

De tal forma, racionalismo e irracionalismo se apresentam como expressões comuns de um mesmo fenômeno, a decadência. O racionalismo operando na cisão entre teoria e prática, na justificação da divisão do trabalho capitalista, contrapõe (uma falsa contraposição) a sociedade ao indivíduo, apresentando-a como "um místico e obscuro poder", ao qual ele é incapaz de compreender. Ao mesmo tempo o irracionalismo se propõe a dar respostas a desumanidade capitalista, mas ao fazer isso aguçou o isolamento dos indivíduos, recomendando a análise para sua interioridade subjetiva, uma vez que o mundo externo objetivo se tornou um lugar ameaçador e incompreensível.

O irracionalismo como concepção do mundo fixa este esvaziamento da alma humana de qualquer conteúdo social, contrapondo-o rígida e exclusivamente ao esvaziamento igualmente mistificado, do mundo do intelecto. Assim, o irracionalismo não se limita a ser a expressão filosófica da barbárie que cada vez mais intensamente domina a vida sentimental do homem, mas a promove diretamente. Paralelamente à decadência do capitalismo e o aguçamento das lutas de classes em decorrência de sua crise, o irracionalismo apela - sempre mais intensamente - aos piores instintos humanos; as reservas de animalidade e de bestialidade que necessariamente se acumulam no homem em regime capitalista. Se as mentirosas fórmulas demagógicas do fascismo, invocadoras do "sangue do solo", puderem encontrar uma tão rápida difusão nas massas pequenas-burguesas seduzidas pelo fascismo, é grande a responsabilidade que recai objetivamente sobre a filosofia e a literatura da decadência, que evocam estes instintos embora na maioria dos casos, não pensassem que deles faria o fascismo, e até mesmo, muito frequentemente, as condenassem com indignação. (LUKÁCS, 2010, p.68)

O irracionalismo não se limita, portanto, a interpretar os sinais da barbárie iminente da sociedade capitalista, vai além disso, ele a alimenta apelando "sempre mais intensamente - aos piores instintos humanos; às reservas de animalidade e de bestialidade que necessariamente se acumulam no homem em regime capitalista" (LUKÁCS, 2010, p.68). Por isso as respostas são cada vez mais mitificadas e violentas, pois encontram, quase sempre, os indivíduos teoricamente despreparados para enfrentar os problemas reais que advém de um modelo social injusto, posto que, fundado na exploração do trabalho humano.

Esse processo de estreitamento da razão, portanto, a separação radical da técnica do campo da significação e dos valores humanos (KOSIK, 2011) e a exaltação da ininteligibilidade do mundo, irá tomar formas mais agressivas no fascismo. O fascismo é a reação autoritária do indivíduo médio, de sua impotência frente a força destruidora do capital. A constante insegurança do seu status médio o coloca em conflito com uma 
iminente situação de retrocesso e medo, dada a possibilidade de uma sociedade igualitária (LUKÁCS,2010).

(...) aos olhos do burguês médio, sua atividade profissional aparece como uma pequena engrenagem num enorme maquinário de cujo funcionamento geral ele não pode ter a mínima ideia. E se esta conexão, esta imprescindível socialidade implícita na vida do indivíduo, é simplesmente negada, ao modo dos anarquistas, nem por isso deixa de se manifestar a separação em compartimentos estanques, com a diferença de que ela recebe agora uma orgulhosa justificação pseudofilosófica. Em ambos os casos, a sociedade aparece, como um místico e obscuro poder, cuja objetividade fatalista e desumanizada se contrapõe, ameaçadora e incompreendida ao indivíduo. (LUKÁCS, 2010, p. 66)

A incompreensibilidade da natureza do funcionamento do capital, manifestada na rígida separação da prática e da teoria, e o temor de perder privilégios de classe moralmente insustentáveis, o coloca na vanguarda da reação ditatorial e coerciva, contra qualquer concepção que possa de algum modo desacreditar o seu estilo de vida, criado pelo capital. Embora o fascismo tenha sido derrotado militarmente em 1945, seu ideário permaneceu em "modo de espera" e sempre pronto para agir quando os interesses do capital assim o necessitasse, mesmo que, imiscuído nas ditaduras militares da América do Sul, no Apartheid sul-africano, ou na contra o oriente promovida pelos Estados Unidos.

\section{A ascensão das pseudociências como aspecto da decadência ideológica}

A revolução democrático-burguesa trouxe a ciência para o centro do debate. $O$ iluminismo teve um papel importante no reconhecimento da ciência como ferramenta para o desvelamento da realidade. Todos os campos do conhecimento humano, poderiam e deveriam ser submetidos à razão. O método científico destronava, desse modo, a autoridade religiosa, juntamente com as crendices, superstições e preconceitos, que haviam imperado durante o período medieval. A ideologia burguesa do período revolucionário tinha como ideal o uso da razão como princípio do progresso da sociedade. Como vimos anteriormente, essa situação irá mudar com o a consolidação do poder burguês e acirramento da luta de classes, que irá produzir uma verdadeira reviravolta na ideologia do progresso, mitigando, necessariamente, todas as investidas para compreender as contradições, transformando-as em sentenças apologéticas do sistema capitalista.

Hobbes e Locke, Helvétius e Holbach foram representantes grandiosos e corajosos da filosofia burguesa do progresso. Decerto, é verdade que traduziram em sistema filosófico as ilusões a respeito do progresso; todavia, dado que as ilusões eram historicamente necessárias, sua expressão filosófica podia e devia conduzir à descoberta, numa forma profunda, de momentos importantes do desenvolvimento histórico real. A defesa do progresso histórico realizado pelo capitalismo é inseparavelmente acompanhada, neles e em seus seguidores, por um corajoso desmascaramento de todas as contradições e horrores da sociedade burguesa que podiam perceber. (LUKÁCS, 2010, p.59). 
Nas ciências sociais "peso das tradições apologéticas" (LUKÁCS, 2010, p.72) cumpriram uma função devastadora. Os limites dados à interpretação da realidade social engendrada pelas forças produtivas do capital, se tornaram cada vez mais estreitos e abalizados pela apologética. O "desmascaramento de todas as contradições" deu lugar a uma análise estatística e superficial dos dados, quando não a sua completa distorção. Metodologicamente, ecletismo e relativismo correspondem as formas pelas quais operam a apologética do capital, disfarçando ou por vezes adornando suas contradições intrínsecas.

A forma cientifica na qual se manifesta este espírito da pequena burguesia capitalista é o ecletismo, a tentativa de erigir como "método" científico o "por um lado... e por outro", tão caro ao pequeno burguês de negar contradições da vida ou, o que é a mesma coisa, de contrapor entre si, de maneira superficial, rígida e carente de mediações determinações contraditórias. Ademais, este ecletismo se veste de roupagens tanto mais suntuosas quanto mais for vazio. Quanto mais se mascarava de "crítico" e "revolucionário", tanto maior é o perigo que representa para as massas trabalhadoras cuja revolta é ainda confusa. (LUKÁCS, 2010 p.60)

Esse tipo de abordagem é muito comum no campo das filosofias pós-modernas, que buscam reduzir a análise objetiva dos fatos, ao jogo das "narrativas", convertendo a ciência em mais uma "metanarrativa" totalizadora. De fato, não há dois lados para tudo. Não houve, "por um lado", nenhum benefício para as populações negras escravizadas trazidas como mercadoria para a trabalhar, até o fim de suas vidas, nas lavouras de café e engenhos de cana de açúcar no Brasil. Não há um lado "positivo" nisso, nem mesmo o fim da escravidão trouxe benefícios substantivos para os descendentes desses povos, que lutam ainda hoje contra o preconceito racial e a marginalização social. Qualquer tentativa de contar a história desses povos de outra forma, que os coloque como beneficiários de alguma herança social, não passa de uma visão torpe da apologética decadente, buscando ocultar a ação do capital sob a vida das pessoas. Em muito dos casos o relativismo é o modo pelo qual a manipulação das ciências sociais irá esconder a essência contraditória da realidade capitalista. "O relativismo, luta contra a aplicação do princípio de causalidade (substituído pela probabilidade estatística), o 'desaparecimento' da matéria: tudo isto é utilizado em larga escala visando difundir um relativismo niilista e um misticismo obscurantista" (LUKÁCS, 2010, p.73).

As ciências naturais não estão livres da apologética, embora sua influência não tenha um alcance tão amplo, quanto nas ciências sociais. Para Lukács (2010), mesmo no 
período de decadência as ciências naturais puras passaram por um amplo desenvolvimento.

A burguesia é obrigada, sob pena de desaparecer, a desenvolver a técnica e consequentemente, também as ciências naturais; ou pelo menos, a permitir um âmbito de jogo relativamente amplo ao desenvolvimento das ciências naturais puras. É por isso que as ciências naturais puderam experimentar um intenso crescimento mesmo no período da decadência. Na natureza, afloram por toda parte os problemas da verdadeira dialética que pressionam cada vez mais a rígida moldura da concepção mecanicista e metafórica do mundo realizam-se, continuamente, novas descobertas teóricas importantíssimas. Contudo, nas condições da época da decadência, torna-se extremamente difícil - e quase impossível - passar de fatos recentemente descobertos e das correspondentes teorias científicas, sua generalização filosófica e uma verdadeira clarificação filosófica dos conceitos básicos" (LUKÁCS, 2010, p.73).

Os limites de interpretação dos fatos científicos impostos pela apologética capitalista aos resultados da ciência, deixou uma porta aberta para que um vasto número de pseudociências autolegitimadoras e mistificadoras da forma capital, ganhassem força material. As pseudociências são tão antigas quanto a própria ciência, mas só ganham expressão política quando passam a representar, de algum modo, os desvarios de uma sociedade em crise. São nas crises que as pseudociências emergem e passam a contribuir para a manipulação da vida cotidiana das pessoas, robustecendo as alienações do mundo real. A característica crucial das hipóteses pseudocientíficas é o fato de que elas dão respostas que confirmam a um conjunto de crenças pessoais que estão ligadas ao tono emocional dos indivíduos. De modo geral, reiteram preconceitos e legitimam injustiças, se adequando estruturalmente a crise. O fascismo e o nazismo alemão são um exemplo claro do uso político da pseudociência, como justificativa das atrocidades cometidas no holocausto.

O período de Hitler representa, nos dois aspectos, o ponto alto alcançado até o momento da irracionalidade que não foi freada por nenhum pensamento. Não só o império mundial alemão enquanto fim a ser alcançado não correspondeu, em momento algum, às reais relações de poder, mas igualmente a ideologia, com a qual deveriam ser resolvidos os problemas que iam surgindo, sobretudo a teoria racial oficial, representa o rompimento mais brusco imaginável com métodos científicos de concepção da realidade até ali alcançados pela humanidade. A absurdidade inerente a tal ideologia é dupla: por um lado, ela representa o rompimento mais brusco imaginável com os métodos de uma elaboração ideal da realidade que já havia se tornado universalmente possível; por outro, lado nas suas funções puramente ideológicas, ela se converte em meio de pensamento para dirimir um conflito que antemão é insolúvel, ou seja, torna-se justamente aquilo que ela orgulhosamente professou ser: um mito. (LUKÁCS, 2013, p.791)

O nazismo foi o ápice do irracionalismo, momento também em que as pseudociências se firmaram como força material e instrumento político da economia 
capitalista. Mas, se havia a necessidade científica de justificar absurdidades ideológicas por meio de pseudociências, como a eugenia e a frenologia, naquele tempo, hoje as pseudociências buscam justificar as ideologias absurdas do neoliberalismo, se colocando contra a ciência até então estabelecida. Assim o revisionismo histórico, o terraplanismo, o movimento antivacina, o negacionismo climático se apresentam como pseudocríticas da ciência normal ${ }^{2}$. Não estão preocupados em comprovar nada, mas em desacreditar a ciência normal, criando o caos e a insegurança adequada ao desenvolvimento do individualismo neoconservador ${ }^{3}$ e protofascista ${ }^{4}$. É importante ressaltar que nos EUA a união entre neoconservadores e neoliberais têm sido a fonte a para o avanço de políticas de austeridade compromissadas com o funcionamento irrestrito do capital.

\section{A decadência ideológica da burguesia brasileira e a apologética do empreendedorismo na produção científica}

A vitória de Jair Bolsonaro elevou o discurso neoconservador intensificando a decadência ideológica da burguesia brasileira. O debate conciliador entre desenvolvimento econômico e inclusão de minorias, dá espaço para um tom mais agressivo de diminuição de direitos como solução da retomada do crescimento econômico. Na política educacional a promoção de Ministros obscurantistas e tecnicamente despreparados para a pasta, vem acompanhada pelo contingenciamento das universidades federais e a retração dos investimentos na pesquisa. Segundo o jornal Folha de S. Paulo em 2019 o Ministério da

\footnotetext{
2 Usamos aqui a definição de Kuhn (2011, p.29) “'Ciência normal' significa a pesquisa firmemente baseada em uma ou mais realizações científicas passadas. Essas realizações são conhecidas durante algum tempo por alguma comunidade científica específica como proporcionando os fundamentos para a sua prática posterior".

${ }^{3}$ Segundo Lima e Hypólito (2019, p.5) "Moll (2015b) afirma que foi o socialista Michael Harrington quem cunhou o termo neoconservadorismo, referindo-se a um novo tipo de conservadorismo, que em alguns pontos partia de princípios similares aos neoliberais. Para o autor, os neoconservadores, 'inspirados no liberalismo clássico, acreditavam que a interferência do governo na economia e os programas sociais geravam inflação, endividamento e prejuízos à produtividade' (MOLL, 2015b, p. 56). Barroco, que também faz uso do termo neoconservador, corrobora tal análise e afirma que este foi um grupo que surgiu a partir da crise mundial do capitalismo dos anos 1970, quando o 'conservadorismo se reatualizou, incorporando princípios econômicos do neoliberalismo, sem abrir mão do seu ideário e do seu modo específico de compreender a realidade' (BARROCO, 2015, p. 624). Assim, para a autora, o neoconservadorismo passa, então, a apresentar-se como forma dominante de apologia conservadora da ordem capitalista, combatendo o Estado Social e os direitos sociais, almejando uma sociedade sem restrições ao mercado e reservando ao Estado a função coercitiva de reprimir violentamente todas as formas de contestação à ordem social e aos costumes tradicionais".

${ }^{4}$ Indicamos aqui o adjetivo "protofascista", para ressaltar que dentro dos valores neoconservadores estão também, de modo rudimentar, os princípios do fascismo.
} 
Ciência e Tecnologia Inovações e Comunicações (MCTIC) sofreu um corte de $42 \%$ do seu orçamento. $\mathrm{O} \mathrm{CNPq}$, maior agência de fomento à pesquisa do país, teve dificuldade para pagar as bolsas de estudo de pesquisadores e precisou paralisar novos editais. Como contrapartida o MEC apresentou um plano de reestruturação das universidades que se mostrou, de partida, insustentável. Segundo o Portal do MEC, o "Future-se" é um programa que busca dar maior autonomia para as universidades federais estimulando a captação de recursos próprios por meio de investimentos da iniciativa privada. $\mathrm{Na}$ verdade, as universidades já captam recursos privados há alguns anos para realização de suas pesquisas e a experiência demonstra que há muito pouco interesse do setor privado em investir em pesquisa e desenvolvimento, a não ser que isso tenha um reconhecido retorno financeiro direto, e muitas pesquisas não possuem essa natureza.

Segundo a PINTEC-IBGE, no período 2006 a 2008, em que as empresas aumentavam sua produção e lucro, o salário aumentava e explodia o recurso disponibilizado para a inovação empresarial, apenas $7 \%$ das empresas inovadoras contataram universidades e institutos de pesquisa em busca de resultados de pesquisas. E, destas, $70 \%$ consideravam essa relação de baixa importância para sua estratégia de inovação. (DANIGNO, ROMÃO e BEZERRA, 2019, p.329)

A novidade do MEC é que com o programa, as universidades terão de abrir mão de sua autonomia constitucional legando sua gestão para Organizações Sociais (OS), abrindo precedentes para a desobrigação do Estado com o financiamento do ensino, pesquisa e extensão universitária (LEHER,2019). Em resumo o programa não passa de uma forma indireta de privatização das Universidades Federais, repleto de erros técnicos, ausente de quaisquer estudos e análises de impacto real sobre as universidades e o desenvolvimento da pesquisa nacional (LEHER, 2019). De outro modo, revela o aprofundamento da decadência ideológica, na "refuncionalização" das universidades em plena afinidade estrutural com o mercado, alterando sua finalidade de instituição para a produção e divulgação do conhecimento, para instituição lucrativa. É importante ressaltar que o projeto não teve nenhuma adesão formal das Instituições Federais, contudo, nos interessa aqui analisar o discurso ideológico do projeto. De fato, seus idealizadores consideraram lograr a comunidade acadêmica com propagandas e slogans vazios reiterando a "inovação" e o "empreendedorismo" da medida. Aqui se destacam dois aspectos taxativos da decadência, a retórica e a escolástica. A retórica já se inicia com o nome do projeto, "Future-se" indica que o modelo atual de universidade é ultrapassado e para sua inclusão no futuro seria necessário deixar o mercado agir sobre seu modo de ser. Isso é o que significa a partícula apassivadora "se", ou seja, a voz passiva recomenda que as universidades recebam a ação do futuro, ao invés de praticá-la. Esse futuro viria então do mercado, da ação 
empreendedora capaz de amplificar a captação de recursos para as universidades. A retórica corresponde a "toda expressão política, científica ou literária que não reflita o movimento real e nem se dê ao trabalho de estudá-lo e expressá-lo, e que, por isso ainda que ocasionalmente toque de leve na verdade, afasta-se cada vez mais da trajetória da curva em direção à tangente" (LUKÁCS, 2010, p.92).

No contexto atual, o empreendedorismo se transformou na retórica do neoliberalismo brasileiro, uma palavra "santa", capaz de resolver e amenizar todos os problemas do desemprego e da deterioração dos recursos do Estado. Entre as classes médias, o empreendedorismo assume o aspecto quase que religioso da transformação uma postura do homem de "Saulo para Paulo", não mais a luta contra o imponderável, mas a aceitação da força do capital. Mudar a si mesmo para que possa ser aceito pelo mercado. É nesse ponto que opera a escolástica.

(...) a escolástica é substancialmente, na ideologia da decadência, um sistema de pensamento extremamente complicado, que trabalha com categorias bastante, sutis e retorcidas, ao qual falta apenas uma ninharia: não referir-se ao núcleo da questão. (LUKÁCS, 2010, p.86)

O empreendedorismo subverte o núcleo da questão da crise capitalista, que é a sua incapacidade de produzir uma solução crível para o problema do desemprego estrutural e empobrecimento das classes médias e trabalhadoras. O problema da acumulação capitalista permanece intacto, o fato de que a riqueza produzida esteja reservada a pouco mais de $10 \%$ da população mundial e que seu crescimento, não signifique necessariamente a sua distribuição, mas ao contrário, na lógica neoliberal, o crescimento econômico está vinculado obrigatoriamente a políticas de austeridade e redução da massa salarial. Este problema central, passa ao largo da compreensão decadente do empreendedorismo, que transforma sutilmente a ação corporativa dos grandes conglomerados capitalistas, em atos decorrentes dos esforços e méritos individuais. A crise de acumulação se reveste de crise moral decorrente de mais ou menos empreendimento. Escolas, universidades, hospitais, são transformados em espaço de empreendimento. Professores, pesquisadores, médicos, advogados, são impelidos a empreender como complemento da renda.

O empreendedorismo se apresenta como uma ideologia irruptiva na sociedade, para a visão schumpeteriana o empreendedor se torna a peça fundamental do desenvolvimento econômico capitalista, uma vez que promove a "destruição criadora", reconhecida como desenvolvimento. 
$\mathrm{Na}$ compreensão de Schumpeter, toda a constituição do desenvolvimento (mudanças espontâneas e descontínuas no canal do fluxo circular, perturbações do centro de equilíbrio) aparece na esfera da vida industrial e comercial, e não na contextura das necessidades dos consumidores de produtos finais. (SANTIAGO, 2009, p.90)

Nessa visão empreender estaria ligado a destruição de antigos produtos e hábitos para a criação de novos. O apologismo ao capital se apresenta abertamente pelo fato de conceber o desenvolvimento estrito da economia capitalista, como forma de desenvolvimento universal. A transferência dessa ideologia do campo econômico para o campo educacional pressupõe o empreendedorismo como comportamento adequado para o enfrentamento da crise social do capitalismo, não como forma de compreensão da realidade, mas como método de tornar mais aceitável e eficiente a mercantilização de toda a sociedade.

O desinvestimento na ciência e a ampliação da esfera do empreendedorismo não é um mero acaso, mas um aspecto da decadência ideológica. O capital incorpora a ciência no aumento de sua produtividade, mas nem toda ciência lhe proporciona a lucratividade almejada. Ao contrário, tem aumentado a quantidade de artigos científicos, tanto das ciências humanas, quanto das ciências exatas, que apontam os efeitos negativos dos empreendimentos capitalistas, sobre a sociedade e a natureza. No entanto, seria impossível eliminar de vez com toda a pesquisa crítica sem comprometer o próprio funcionamento do capital. A saída é otimizar os recursos, estimulando o empreendedorismo no campo da pesquisa para obter retornos mais lucrativos e uma certa positividade, do ponto de vista do capital, dos resultados científicos. É o que podemos observar no artigo 19 do Future-se:

É assegurada participação nos ganhos econômicos resultantes da exploração de direito de propriedade intelectual, durante toda a sua vigência, ao servidor público federal que desenvolver invenção, aperfeiçoamento ou modelo de utilidade e desenho industrial, bem como à Instituição Federal de Ensino Superior a que pertence o servidor. (BRASIL, 2019, p.17)

Nas entrelinhas lê-se o incentivo a pesquisa lucrativa e objeção da ciência que contradiga o imperativo da produtividade capitalista. A margem para o surgimento de pesquisas "desinteressadas" se torna cada vez mais estreita, enquanto que o redirecionamento dos gastos públicos com a ciência, normatiza e recompensa o "mercenarismo" intelectual.

Seria impossível pensar em desenvolvimento, sem investimentos em ciência e tecnologia, contudo, em contextos particulares em que sejam necessários recombinar 
formas de atuação para criar novos produtos e novos mercados, o desiquilíbrio de áreas consolidadas, como a produção científica brasileira, possibilitaria o surgimento de "inovações" 5 que permitam auferir novos mercados e novos lucros para o empresariado. A construção desse cenário, portanto, não é ocasional. Ele retrata os aspectos da decadência ideológica da burguesia brasileira. Coloca a produção científica nacional estrategicamente numa situação de fragilidade, acentuando o avanço de posturas agressivas, tanto na exploração máxima dos recursos naturais, quanto na expropriação máxima do trabalho, submetendo a classe trabalhadora à níveis degradantes de vida.

\section{Considerações Finais}

Neste artigo expusemos, ao largo, as características da decadência ideológica da burguesia, segundo os pressupostos de Lukács (2010). Ao expor os traços gerais do processo de decadência buscou-se analisar a situação do avanço das pseudociências no contexto da crise social do modelo capitalista, destacando o seu papel na desvalorização e descredibilização da ciência normal perante a sociedade. As pseudociências estariam, portanto, ligadas a desestabilização da pesquisa científica, ao mesmo tempo em que abrem espaço para o avanço do irracionalismo e autoritarismo da dinâmica retorcida da produção capitalista. A crise que assola o capitalismo desde o fim do welfare states, apresenta o completo desequilíbrio do Estado e de áreas antes consolidadas, como solução para a retomada da lucratividade dos empresários. As ciências não poderiam ficar de fora. No Brasil a pesquisa científica é financiada quase que na sua totalidade por investimentos estatais e realizada no interior das universidades públicas, que por sua vez abriga uma diversidade de pesquisas que vão desde o mapeamento do genoma humano, até as pesquisas de gênero e diversidade social. No entanto, transformar toda a atividade científica numa atividade lucrativa para os empresários é de início, um contrassenso. Nesse sentido a ação da apologética sobre a produção científica nacional, majorou o discurso decadente das pseudociências, salvaguardando os interesses do grande capital ${ }^{6}$, na mesma medida em que busca desestabilizar a ciência nacional, para dar-lhe feições

\footnotetext{
5 Vale lembrar que para a visão schumpeteriana, uma inovação “(...) de modo algum precisa ser baseada numa descoberta cientificamente nova” (SCHUMPETER,1997, p.76), o essencial é que ela possibilite o lucro empresarial.

${ }^{6}$ São indiscutíveis hoje as influências do grande agronegócio nas alterações climáticas regionais, nas intoxicações causadas pelo uso indiscriminado de agrotóxicos e no grande custo hídrico na manutenção de suas monoculturas; para setores como esse, pesquisas que demonstram as relações causais entre os efeitos corrosivos e poluidores da produtividade capitalista, são consideradas improdutivas e indesejáveis e poderiam deixar de receber investimentos
}

Cadernos GPOSSHE On-line, Fortaleza, v. 2, n. Especial, 2019. 
empresariais. Assim nasce o "Future-se". Fruto do triunfo da política neoconservadora, o programa encaminhado pelo ministro Abraham Wientraub, procura disciplinar os recursos destinados à pesquisa nas universidades federais e direcioná-los à uma produção mais lucrativa das pesquisas brasileiras. Imbuído da apologética do empreendedorismo, o "Future-se", prevê estímulos para professores e universidades empreendedoras, na outra ponta, desobriga o Estado dos investimentos constitucionais.

Por fim, a ideia de uma política científica inovadora, como proposta pelo MEC, objetiva de outro modo, o cerceamento da ciência aos ditames do mercado, reduzindo a capacidade da produção científica do país. Não apenas reduzir a competência de produzir novas descobertas, mas principalmente diminuir a capacidade de realizar a crítica dos métodos empreendidos na obtenção da lucratividade capitalista. 


\section{REFERÊNCIAS}

BRASIL. Programa Institutos e Universidades Empreendedoras e Inovadoras - FUTURESE, e dá outras providências, 2019. In: In: DOSSIÊ SOBRE O PROGRAMA FUTURE-SE: DO GOVERNO/MEC E AS IMPLICAÇÕES PARA A UNIVERSIDADE E A SOCIEDADE. $2^{2}$ ed.Centro de Estudos e Pesquisas em Humanidades/CRH-UFBA: Grupo de Pesquisa Trabalho, Precarização e Resistências Outubro ,2019. Disponível em: <https://gtfuturese.paginas.ufsc.br/files/2019/08/Dossie\%CC\%82-FUTURE-SE-ufba.pdf> Acesso em 20 de janeiro de 2020.

DAGNINO, Renato; ROMÃO, Wagner; BEZERRA, Rogério. Universidades - FUTURE-SE e o aporte de recursos de empresas. In: DOSSIÊ SOBRE O PROGRAMA FUTURE-SE: DO GOVERNO/MEC E AS IMPLICAÇÕES PARA A UNIVERSIDADE E A SOCIEDADE. 2a.ed Centro de Estudos e Pesquisas em Humanidades/CRH-UFBA: Grupo de Pesquisa Trabalho, Precarização e Resistências Outubro ,2019. Disponível em: <https://gtfuturese.paginas.ufsc.br/files/2019/08/Dossie\%CC\%82-FUTURE-SE-ufba.pdf> Acesso em 20 de janeiro de 2020.

KOSIK, K. A dialética do concreto. 9ª ed. Trad. Célia Neves e Alderico Toríbio. São Paulo: Paz e Terra, 2011.

KUH N, T. A estrutura das revoluções científicas. 11ㄹ. ed. Trad. Beatriz Viana Boeria e Nelson Boeira. São Paulo: Perspectica, 2011.

LEHER, R. Análise preliminar do "FUTURE-SE" indica a refuncionalização das Universidades e Institutos Federais. In. DOSSIÊ SOBRE O PROGRAMA FUTURE-SE: DO 
GOVERNO/MEC E AS IMPLICAÇÕES PARA A UNIVERSIDADE E A SOCIEDADE. 2a.ed Centro de Estudos e Pesquisas em Humanidades/CRH-UFBA: Grupo de Pesquisa Trabalho, Precarização e Resistências Outubro ,2019. Disponível em: <https://gtfuturese.paginas.ufsc.br/files/2019/08/Dossie\%CC\%82-FUTURE-SE-ufba.pdf> Acesso em 20 de janeiro de 2020.

LIMA, I. G. e HYPÓLITO, A. M. A expansão do neoconservadorismo na educação brasileira. In: Educação e Pesquisa, São Paulo, v. 45, e190901, 2019. Disponível em: <http://www.scielo.br/pdf/ep/v45/1517-9702-ep-45-e190901.pdf> Acesso em: 8 de janeiro de 2010.

LUKÁCS, G. Marxismo e teoria da literatura. 2ª̀.ed. Trad. Carlos Nelson Coutinho. São Paulo: Expressão Popular, 2010.

LÚKÁCS. G. Para uma ontologia do ser social II. Trad. Nélio Schneider, Ivo Tonet e Ronaldo Viemi Fortes. São Paulo: Boitempo, 2013.

MARX, K. O Capital: crítica da economia política. Livro I. $27^{\mathrm{a}}$.ed. Trad. Reginaldo Sant'Anna. Rio de Janeiro: Civilização Brasileira, 2010.

MARX, K. e ENGELS, F. O manifesto comunista. 19ª reimpressão. Trad. Maria Lúcia Como. Rio de Janeiro: Paz e Terra, 2009.

SANTIAGO, E. G. Vertentes teóricas sobre empreendedorismo em Schumpeter, Weber e Mcclelland: novas referências para a sociologia do trabalho. Revista de Ciências Sociais, v. 40, $\quad$ n. 2,2009 p. 87-103. Disponível em: $<$ file://C:/Users/Compaq/Documents/Downloads/488-Texto\%20do\%20artigo-671-1-1020130305.pdf>Acesso em: 20 de janeiro de 2020.

SCHUMPETER, J. A. Teoria do desenvolvimento econômico: uma investigação sobre lucros, capital, crédito, juro e o ciclo econômico. Trad. Maria Silvia Possas. São Paulo: Nova Cultural, 1997. 